\title{
Genomics, cys-loop ligand-gated ion channels and new targets for the control of insect pests and vectors
}

\author{
Andrew K Jones \\ Department of Biological and Medical Sciences, Faculty of Health and Life Sciences, Oxford Brookes University, \\ Oxford, OX3 OBP, UK \\ Correspondence: a.jones@brookes.ac.uk; Tel.: +44-(0)1865-483602
}

\section{Short Title}

Insect cys-loop ligand-gated ion channels

\begin{abstract}
Cys-loop ligand-gated ion channels (cysLGICs) play roles in the nervous system. They consist of five subunits arranged around a central ion channel with each subunit being encoded for by a separate gene. In insects, the cysLGIC superfamily commonly consists of 21-25 genes giving rise to several receptor classes such as nicotinic acetylcholine receptors and GABA receptors. Insect cysLGICs are of interest as they are the target of insecticides. Analyses of genome sequences have identified cysLGIC gene superfamilies from different species including crop pests, disease vectors and beneficial insects. This review explores recent studies that have pushed forward our knowledge about this superfamily and considers the potential of developing improved strategies to control insect pests whilst sparing non-target organisms.
\end{abstract}

\section{Highlights}

- Aedes aegypti cysLGIC superfamily is the most recent one to be characterised

- Some insect cysLGICs may perform non-neuronal roles

- Insect glycine receptor subunits have potentially been discovered

- Differences in insect cysLGICs may be exploited to develop improved insecticides 


\section{Introduction}

Cys-loop ligand-gated ion channels (cysLGICS) make up a superfamily of receptors, for which the bestknown role is to mediate the actions of neurotransmitters (sometimes referred to as agonists) in sending signals throughout the nervous system. CysLGICs act as molecular switches, which change conformation upon binding to an agonist to allow a net influx of ions into the cell [1]. They consist of five subunits arranged around a central ion channel (Figure 1). Each subunit has four transmembrane domains (TM1-4) and possesses an N-terminal extracellular domain containing the characteristic Cysloop motif consisting of two disulphide bond-forming cysteines separated by 13 amino acid residues. In insects, neurotransmitters known to act on cysLGICs in this way include acetylcholine (ACh), $y$ aminobutyric acid (GABA), glutamate and histamine. The neurotransmitter binding site is located at the interface of two adjacent subunits and is formed by six distinct regions (loops A-F [2]) in the Nterminal extracellular domain with loops $A, B$ and $C$ being contributed by one subunit and loops $D, E$ and $\mathrm{F}$ by another. CysLGICs can exist either as homomers, where all five subunits are the same, or as heteromers consisting of at least two different subunits. The subunit composition determines the functional and pharmacological properties of the cysLGIC, thus receptor diversity is generated by multiple subunit-encoding genes in a given organism. As will become apparent throughout this review, insect cysLGICs are of interest as they are involved in various aspects of nervous system function as well as being the molecular targets of highly effective insecticides.

Sequencing of insect genomes have allowed for detailed comparisons of cysLGIC gene families from diverse species (Table 1). From Table 1, it can be seen that the number of cysLGIC genes are similar from one species to another, ranging from 21 to 26 genes. Many subunits are highly conserved in different species, which is highlighted by recently characterised cysLGIC superfamilies from the tiger mosquito, Aedes aegypti (BJ Matthews et al., unpublished), the bumble bee Bombus terrestris [3] and the pea aphid Acyrthosiphon pisum (del Villar and Jones, unpublished) [4], which are shown in a phylogenetic tree in Figure 2. The cysLGICs have been grouped according to the neurotransmitter they respond to. These groups are briefly considered in turn below with specific focus on recent developments.

\section{Nicotinic acetylcholine receptors}

Nicotinic acetylcholine receptors ( $n A C h R s$ ) mediate the fast actions of acetylcholine (ACh). Subunits are denoted as $\alpha$ subunits due to the presence of two adjacent cysteine residues in loop $C$, which are important for ACh binding [5]. nAChR subunits lacking these two cysteines are referred to as $\beta$. To be functional, nAChRs require at least two of the subunits to be $\alpha$. As shown in Figure 2, A. pisum, Ae. aegypti and $B$. terrestris possess 11,15 and 11 nAChR subunit genes, respectively. Insects have core groups of subunits $(\alpha 1-8, \beta 1)$ that are highly conserved between species and therefore, presumably, play important roles [6]. Interestingly, A. pisum lacks an $\alpha 5$ subunit (Figure 2 ). The aphid cysLGIC gene superfamily is the most primitive one characterised to date, thus it has been speculated that the $\alpha 5$ subunit is the newest member of the insect core group of subunits appearing in more highly evolved species [4]. nAChRs have been long known to play important roles in the insect nervous system. For example, a recent study showed, using RNA interference, that $\alpha 1, \alpha 4, \alpha 5$, and $\alpha 6$ (but not $\alpha 3$ ) nAChR subunits are involved in olfactory memory processing in Drosophila [7].

nAChRs are the molecular targets of neonicotinoid insecticides $[8,9]$, three of which (imidacloprid, clothianidin and thiamethoxam) will be banned, most likely by the end of 2018, from outdoor use by the European Union amidst fears that they are contributing to the alarming decline of 
bees and other non-target organisms (BBC Science and Environment News; URL: https://www.bbc.co.uk/news/science-environment-43910536). Several other classes of insecticides, such as spinosyns, sulfoxamines and butenolides, act on nAChRs [9]. Also, natural peptides found in venom, such as that of the funnel-web spider, can act on insect nAChRs, with a higher selectivity than on vertebrate $\mathrm{nAChRs}[10]$.

Recent studies have highlighted particular nAChR subunits as being the targets of certain insecticides. For instance, the neonicotinoids nitenpyram and imidacloprid, stimulated dopamine release in nerve cords of Drosophila melanogaster larvae by acting as agonists on nAChRs [11]. This dopamine release was significantly lower in Drosophila with mutations in the $\alpha 1$ and $\beta 2 \mathrm{nAChRs}$ subunits, indicating that these two subunits are important for the actions of both neonicotinoids. The $\beta 1$ subunit has also been implicated as an important neonicotinoid target since the R81T mutation is associated with neonicotinoid resistance in aphids [12] although the mutation can affect neonicotinoids differentially depending on whether the insecticide has a cyano or nitro chemical group [13]. The use of RNAi and patch-clamp electrophysiology on cockroach (Periplaneta americana) dorsal unpaired median neurons indicated that the $\alpha 3$ and $\alpha 8$ subunits may also form part of nAChRs targeted by imidacloprid [14].

Another class of insectcides, spinosyns, acts on a different nAChR subunit, $\alpha 6$, as indicated by recent findings that there were significantly more truncated forms of the $\alpha 6$ subunit in the flower thrips, Frankliniella occidentalis, which were resistant to spinosad [15]. Also, altered $\alpha 6$ mRNA, which lacked exon 3, was found at higher levels in the tomato leaf miner, Tuta absoluta, that were resistant to spinosad [16]. The CRISPR/Cas9 system capable of making desired changes in genome sequences [17] was used to show that the G275E point mutation in $\alpha 6$ of Drosophila flies confers decreased sensitivity to spinosad [18], demonstrating this subunit as being important for spinosyn action.

It remains to be seen which $\mathrm{nAChR}$ subunits are targeted by other insecticide classes. It will be of interest to see whether different insecticide classes act on the same handful of subunits or whether the whole nAChR gene family can effectively be targeted. Genome editing with CRISPR/Cas9 or the use of model organisms such as $D$. melanogaster with the function of whole genes effectively removed may help to answer this question. Indeed, D. melanogaster with a knockout of the $\alpha 1 \mathrm{nAChR}$ gene was resistant to imidacloprid and nitenpyram [19]. Consistent with this, it was found that RNAi of $\alpha 1$ in Leptinotarsa decemlineata decreased sensitivity to imidacloprid and thiamethoxam [20]. Perhaps similar approaches on all nAChR subunits may aid in elucidating which subunits are important for the actions of the various insecticide classes.

In addition to the core nAChR subunits, insects possess at least one divergent subunit that shows low sequence similarity to all other known nAChR subunits [6]. Unlike core group subunits, analogous divergent subunits in different insects are difficult to assign. It is common for each insect species to possess a different set of divergent nAChR subunits. For example, B. terrestris possesses two divergent subunits (Figure 2) whilst Ae. aegypti has a notably large set consisting of two $\alpha$ and four $\beta$ subunits. Less is known about the function of divergent subunits than core ones and it would be of interest to see if they perform species-specific roles. Recently, it has been shown that the divergent subunit from Locusta migratoria $(\beta 3)$ is part of a high affinity binding site for imidacloprid [21], highlighting the possibility that divergent $n A C h R$ subunits may be targets of insecticides, at least in some species. Divergent $n A C h R$ subunits may, therefore, be of interest as targets to control certain insect pests. 


\section{GABA-gated ion channels}

The subunit RDL (resistance to dieldrin) is commonly thought of as the insect GABA receptor although RDL can co-assemble with LCCH3 whilst LCCH3 and GRD can co-assemble to form GABA-gated cation channels [22]. RNAi of $R d l$ in a subset of neurons in $D$. melanogaster results in overconsumption, showing that this subunit is required for proper control of consumption [23], highlighting the important role RDL plays in the nervous system.

Insect GABA receptors are the targets of several insecticide classes including cyclodienes, phenylpyrazoles and isoxazolines [24]. An alanine-to-serine mutation in the second transmembrane domain (A2'S) underlies resistance to cyclodienes, such as dieldrin [25-27]. A mutation at this site, either to serine or another residue such as glycine, has been commonly found in insecticide-resistant insects of diverse species. In some cases, mutations at other sites in RDL have been identified although always together with the TM2 mutation [26-28]. The mutation at the A2 site, therefore, is commonly used as a diagnostic marker for resistance. Recent studies have shown that mutation at TM2 can reach high levels in insect populations. For example, $77-100 \%$ of Anopheles sinensis mosquitoes collected from different geographical locations across Guangxi, China, had the A2'S mutation [28]. Despite the prevalence of this mutation, RDL is still a target of interest for insect control as certain classes of insecticides, such as isoxazolines, can still act on the GABA receptor with the A2' mutation [29].

RDL can be expressed as a homomeric receptor in heterologous expression systems such as Xenopus laevis oocytes giving the impression that it is a relatively simple receptor. This impression, however, is likely to be false as alternative splicing and RNA A-to-I editing of $R d l$ transcripts can considerably increase receptor diversity [27]. Recently, it has been shown that RNA A-to-I editing, which can alter up to six amino acid residues in An. gambiae RDL, can give rise to at least 24 different RDL isoforms [30]. Furthermore, it was shown that editing at just one site can affect the potency of ivermectin, highlighting that RNA editing may affect sensitivity to insecticides in a species-specific manner.

\section{Glutamate-gated chloride channels}

Glutamate-gated chloride channels ( $\mathrm{GluCls}$ ) are the targets of macrocyclic lactones, such as ivermectin and abamectin [31], as was well as promising new insecticide classes, an example of which are okaramines [32]. Recent studies of insect GluCls have reinforced our knowledge concerning resistance mechanisms and the importance of $\mathrm{GluCl}$ as an insecticide target. For example, RNAi of $\mathrm{GluCl}$ in Bemisia tabaci resulted in increased tolerance to abamectin [33] whilst mutations in TM3 of Plutella xylostella $\mathrm{GluCl}$ or M. domestica $\mathrm{GluCl}$ affected abamectin [34] or ivermectin actions [35], respectively.

\section{Histamine-gated chloride channels}

Compared to other cysLGICs, histamine-gated chloride channels (HisCls) have been studied to a lesser degree. However, a recent study that expressed HisCl1 (otherwise known as HCLB) and HisCl2 (HCLA) from $M$. domestica in Xenopus oocytes enhanced our knowledge concerning the pharmacological properties of these ion channels [36]. Both subunits responded to histamine whilst only HisCl1 was activated by GABA and to a lesser degree by choline, serotonin, tyramine and dopamine. His $\mathrm{Cl} 1$ was not affected by insecticides such as fipronil and fluralaner and was only marginally activated by ivermectin. Given that $\mathrm{His} \mathrm{Cl} 1$ is involved in important neuronal processes such as sleep regulation [37] $\mathrm{HisCls}$ may represent targets for future insecticides with novel pharmacological properties. 


\section{pH-sensitive chloride channels}

As is the case for HisCls, our recent knowledge about pH-sensitive chloride channels (pHCls) comes from expressing these ion channels in Xenopus oocytes. Ivermectin was found to activate or block $B$. mori $\mathrm{pHCl}$ in a $\mathrm{pH}$-dependent manner whilst fipronil had no effect [38].

\section{Insect Group 1 of cysLGIC subunits}

Similar to divergent nAChRs, there are cysLGIC subunits in a group denoted Insect Group 1 of cysLGIC subunits [39] that show low sequence homology to other subunits and therefore it is difficult to assign them orthologous relationships between different species. Furthermore, the number of subunits falling into this group varies between species [40]. In Drosophila, these subunits are CG6927, CG7589 and CG11340 whilst in other species they have been called CLGC (ㄷys-loop ligand-gated ion channel) [39] (Figure 2). The function of these subunits was unknown until recently where CG6927, CG7589 and CG11340 were found to be expressed in non-neuronal tissues with possible roles outside of neurotransmission including regulating fluid secretion and mediating the response to osmotic stress $[40,41]$. CG11340 is capable of forming an ion channel in Xenopus oocytes that is sensitive to $\mathrm{pH}$ but not to several neurotransmitters including acetylcholine, GABA, glutamate, glycine, histamine, serotonin, dopamine, tyramine and octopamine [41]. The low levels of conservation of Group 1 cysLGIC subunits raises the prospect of these subunits as potential targets of insecticides that act preferentially on pest species. D. melanogaster with knockout of CG11340 were viable showing that this subunit would not be an effective insecticide target [40]. However, CG7589 appears to be a more promising target as RNAi of this subunit resulted in reduced viability [40].

\section{CG8916 and CG12344}

These two subunits remain the least characterised of the insect cysLGIC superfamily. Analysis of RNA in specific cell types identified CG8916 as being highly expressed in Drosophila T4/T5 neurons along with LCCH3 [42]. CG8916 clusters with subunits gated by GABA (Figure 2) so perhaps it assembles with GRD, LCCH3 or RDL to diversify GABA receptor function. More recently, RNAi studies implicated CG12344, GRD and CG7589 in mediating responses to glycine in Drosophila dorsal neurons identifying for the first time potential insect cysLGIC glycine receptors analogous to that found in vertebrates [43].

\section{Challenges and Future Prospects}

The upcoming ban of neonicotinoid insecticides in Europe stresses the importance of developing insecticides that are selective for pest species whilst sparing beneficial insects and non-target organisms. The characterisation of complete cysLGIC gene superfamilies from insects ranging from crop pests, disease vectors to pollinators (Table 1) highlights differences that perhaps can be exploited in developing ways to specifically target a particular species. The obvious differences lie in the divergent subunits which show low sequence homology between species. Targeting these subunits may offer a route to control particular pests. However, the fact that they are divergent indicates that they have not been constrained by evolution and therefore may not be performing a vital role. Gene targeting approaches to knock out or silence these subunits, such as by CRISPR/Cas or RNAi, may help to determine their importance for a given insect and thus evaluate their potential as an insecticide 
target. Even the more conserved subunits have sequence differences between species that can be exploited. Knowledge of these differences in conjunction with the use of three-dimensional models will likely prove useful in adopting a rational approach to developing compounds that bind more specifically to a cysLGIC from a pest species. However, at present, 3-D models of insect cysLGICs based on structures from other organisms such as vertebrates (E.g. the $\alpha 4 \beta 2 \mathrm{nAChR}$ [44]), molluscs (acetylcholine binding protein AChBP [45]) or nematodes (GluCl [46]) are being relied upon [47]. The low sequence conservation limits the accuracy of these homology models. For example, the extracellular $\mathrm{N}$-terminal domain of the $A$. pisum $\alpha 1$ nAChR subunit shares $48 \%$ and $25 \%$ sequence identity with the human $\alpha 4$ nAChR subunit and molluscan AChBP, respectively. Determining the crystal structure of actual insect cysLGICs would greatly improve the accuracy of 3-D models. Differences in CysLGIC sequences between species may also be exploited for more novel approaches to insect control, such RNAi [48], where sequences particular to pests could be targeted to silence specific subunits.

Whilst genome sequences have helped us in identifying the full complement of cysLGIC subunits in diverse insect species, we still know very little about the receptors themselves. For instance, how do the dozen or so nAChR subunits in a given insect combine together to form the various subtypes of nicotinic acetylcholine receptors? Does the insect GABA receptor just consist of the RDL subunit? Does GRD form either GABA or glycine receptors depending on which subunits it combines with? A major challenge in characterising the insect cysLGICs, therefore, would be to determine how the different subunits assemble to make up native receptors in vivo.

\section{Acknowledgements}

This research did not receive any specific grant from funding agencies in the public, commercial, or not-for-profit sectors.

\section{References}

[1] Nemecz A, Prevost MS, Menny A, Corringer PJ: Emerging Molecular Mechanisms of Signal Transduction in Pentameric Ligand-Gated Ion Channels. Neuron 2016, 90:452-470.

[2] Corringer PJ, Le Novere N, Changeux JP: Nicotinic receptors at the amino acid level. Annu Rev Pharmacol Toxicol 2000, 40:431-458.

[3] Sadd BM, Barribeau SM, Bloch G, de Graaf DC, Dearden P, Elsik CG, Gadau J, Grimmelikhuijzen CJ, Hasselmann $M$, Lozier JD, et al.: The genomes of two key bumblebee species with primitive eusocial organization. Genome Biol 2015, 16:76.

[4] Dale RP, Jones AK, Tamborindeguy C, Davies TG, Amey JS, Williamson S, Wolstenholme A, Field LM, Williamson MS, Walsh TK, et al.: Identification of ion channel genes in the Acyrthosiphon pisum genome. Insect Mol Biol 2010, 19 Suppl 2:141-153.

[5] Kao PN, Karlin A: Acetylcholine receptor binding site contains a disulfide cross-link between adjacent half-cystinyl residues. J Biol Chem 1986, 261:8085-8088.

[6] Jones AK, Sattelle DB: Diversity of insect nicotinic acetylcholine receptor subunits. Adv Exp Med Biol 2010, 683:25-43.

[7] Barnstedt O, Owald D, Felsenberg J, Brain R, Moszynski JP, Talbot CB, Perrat PN, Waddell S: Memory-Relevant Mushroom Body Output Synapses Are Cholinergic. Neuron 2016, 89:1237-1247. [8] Casida JE: Neonicotinoids and Other Insect Nicotinic Receptor Competitive Modulators: Progress and Prospects. Annu Rev Entomol 2018, 63:125-144. 
[9] Ihara M, Buckingham SD, Matsuda K, Sattelle DB: Modes of Action, Resistance and Toxicity of Insecticides Targeting Nicotinic Acetylcholine Receptors. Curr Med Chem 2017, 24:2925-2934. [10] Windley MJ, Vetter I, Lewis RJ, Nicholson GM: Lethal effects of an insecticidal spider venom peptide involve positive allosteric modulation of insect nicotinic acetylcholine receptors.

Neuropharmacology 2017, 127:224-242.

[11] Pyakurel P, Shin M, Venton BJ: Nicotinic acetylcholine receptor (nAChR) mediated dopamine release in larval Drosophila melanogaster. Neurochem Int 2018, 114:33-41.

[12] Bass C, Puinean AM, Andrews M, Cutler P, Daniels M, Elias J, Paul VL, Crossthwaite AJ, Denholm I, Field LM, et al.: Mutation of a nicotinic acetylcholine receptor beta subunit is associated with resistance to neonicotinoid insecticides in the aphid Myzus persicae. BMC Neurosci 2011, 12:51. [13] Hirata K, Jouraku A, Kuwazaki S, Kanazawa J, Iwasa T: The R81T mutation in the nicotinic acetylcholine receptor of Aphis gossypii is associated with neonicotinoid insecticide resistance with differential effects for cyano- and nitro-substituted neonicotinoids. Pestic Biochem Physiol 2017, 143:57-65.

[14] Sun H, Liu Y, Li J, Cang X, Bao H, Liu Z: The potential subunits involved in two subtypes of alphaBgt-resistant nAChRs in cockroach dorsal unpaired median (DUM) neurons. Insect Biochem $\mathrm{Mol}$ Biol 2017, 81:32-40.

[15] Wan Y, Yuan G, He B, Xu B, Xie W, Wang S, Zhang Y, Wu Q, Zhou X: Foccalpha6, a truncated nAChR subunit, positively correlates with spinosad resistance in the western flower thrips, Frankliniella occidentalis (Pergande). Insect Biochem Mol Biol 2018, 99:1-10.

[16] Berger M, Puinean AM, Randall E, Zimmer CT, Silva WM, Bielza P, Field LM, Hughes D, Mellor I, Hassani-Pak K, et al.: Insecticide resistance mediated by an exon skipping event. Mol Ecol 2016, 25:5692-5704.

[17] Jinek M, Chylinski K, Fonfara I, Hauer M, Doudna JA, Charpentier E: A programmable dual-RNAguided DNA endonuclease in adaptive bacterial immunity. Science 2012, 337:816-821.

[18] Zimmer CT, Garrood WT, Puinean AM, Eckel-Zimmer M, Williamson MS, Davies TG, Bass C: A CRISPR/Cas9 mediated point mutation in the alpha 6 subunit of the nicotinic acetylcholine receptor confers resistance to spinosad in Drosophila melanogaster. Insect Biochem Mol Biol 2016, 73:62-69.•• This is an elegant example of the use of the revolutionary CRISPR/Cas9 system to demonstrate the importance of a particular cysLGIC subunit in insecticide action, in this case by introducing a mutation associated with insecticide resistance.

[19] Somers J, Luong HNB, Batterham P, Perry T: Deletion of the nicotinic acetylcholine receptor subunit gene Dalpha1 confers insecticide resistance, but at what cost? Fly (Austin) 2018, 12:46-54. [20] Qu Y, Chen J, Li C, Wang Q, Guo W, Han Z, Jiang W: The subunit gene Ldalpha1 of nicotinic acetylcholine receptors plays important roles in the toxicity of imidacloprid and thiamethoxam against Leptinotarsa decemlineata. Pestic Biochem Physiol 2016, 127:51-58.

[21] Bao H, Liu Y, Zhang Y, Liu Z: Two distinctive beta subunits are separately involved in two binding sites of imidacloprid with different affinities in Locusta migratoria manilensis. Pestic Biochem Physiol 2017, 140:36-41.

[22] Buckingham SD, Biggin PC, Sattelle BM, Brown LA, Sattelle DB: Insect GABA receptors: splicing, editing, and targeting by antiparasitics and insecticides. Mol. Pharmacol 2005, 68:942-951.

[23] Cheung SK, Scott K: GABAA receptor-expressing neurons promote consumption in Drosophila melanogaster. PLoS One 2017, 12:e0175177.• This is an excellent example of utilising the Drosophila melanogaster model organism to determine the function of cysLGIC subunits in particular cell types, in this case discerning that RDL in a subset of neurons regulates feeding.

[24] Buckingham S, Ihara M, Sattelle DB, Matsuda K: Mechanisms of action, resistance and toxicity of insecticides targeting GABA receptors. Curr. Med. Chem 2017, 24:2935-2945.

[25] Ffrench-Constant RH, Rocheleau TA, Steichen JC, Chalmers AE: A point mutation in a Drosophila GABA receptor confers insecticide resistance. Nature 1993, 363:449-451.

[26] Nakao T: Mechanisms of resistance to insecticides targeting RDL GABA receptors in planthoppers. Neurotoxicology 2017, 60:293-298. 
[27] Taylor-Wells J, Jones AK: Variations in the insect GABA ieceptor, RDL, and their impact on receptor pharmacology. In Advances in Agrochemicals: Ion Channels and $G$ Protein-Coupled Receptors (GPCRs) as Targets for Pest Control. Edited by Gross AD, Ozoe Y, Coats JR: ACS Publications; 2017:1-21. ACS Symposium Series eBooks, vol 2.]

[28] Yang C, Huang Z, Li M, Feng X, Qiu X: RDL mutations predict multiple insecticide resistance in Anopheles sinensis in Guangxi, China. Malar J 2017, 16:482.

[29] Rufener L, Danelli V, Bertrand D, Sager H: The novel isoxazoline ectoparasiticide lotilaner (Credelio): a non-competitive antagonist specific to invertebrates gamma-aminobutyric acid-gated chloride channels (GABACls). Parasit Vectors 2017, 10:530.

[30] Taylor-Wells J, Senan A, Bermudez I, Jones AK: Species specific RNA A-to-I editing of mosquito RDL modulates GABA potency and influences agonistic, potentiating and antagonistic actions of ivermectin. Insect Biochem Mol Biol 2018, 93:1-11.•• This study highlights how RNA editing can produce a considerably large number of products from a single gene and that this can alter the pharmacological properties of a cysLGIC in a species-specific manner, including the response to certain insecticides.

[31] Wolstenholme AJ: Glutamate-gated chloride channels. J. Biol. Chem 2012, 287:40232-40238.

[32] Kato N, Furutani S, Otaka J, Noguchi A, Kinugasa K, Kai K, Hayashi H, Ihara M, Takahashi S, Matsuda K, et al.: Biosynthesis and Structure-Activity Relationship Studies of Okaramines That Target Insect Glutamate-Gated Chloride Channels. ACS Chem Biol 2018, 13:561-566.

[33] Wei P, Che W, Wang J, Xiao D, Wang R, Luo C: RNA interference of glutamate-gated chloride channel decreases abamectin susceptibility in Bemisia tabaci. Pestic Biochem Physiol 2018, 145:1-7. [34] Wang X, Puinean AM, AO OR, Williamson MS, Smelt CLC, Millar NS, Wu Y: Mutations on M3 helix of Plutella xylostella glutamate-gated chloride channel confer unequal resistance to abamectin by two different mechanisms. Insect Biochem Mol Biol 2017, 86:50-57.

[35] Fuse T, Kita T, Nakata Y, Ozoe F, Ozoe Y: Electrophysiological characterization of ivermectin triple actions on Musca chloride channels gated by l-glutamic acid and gamma-aminobutyric acid. Insect. Biochem. Mol. Biol 2016, 77:78-86.

[36] Kita T, Irie T, Nomura K, Ozoe F, Ozoe Y: Pharmacological characterization of histamine-gated chloride channels from the housefly Musca domestica. Neurotoxicology 2017, 60:245-253.

[37] Oh Y, Jang D, Sonn JY, Choe J: Histamine-HisCl1 receptor axis regulates wake-promoting signals in Drosophila melanogaster. PLoS One 2013, 8:e68269.

[38] Nakatani Y, Furutani S, Ihara M, Matsuda K: Ivermectin modulation of pH-sensitive chloride channels in the silkworm larvae of Bombyx mori. Pestic Biochem Physiol 2016, 126:1-5.

[39] Jones AK, Sattelle DB: The cys-loop ligand-gated ion channel gene superfamily of the red flour beetle, Tribolium castaneum. BMC Genomics 2007, 8:327.

[40] Remnant EJ, Williams A, Lumb C, Yang YT, Chan J, Duchene S, Daborn PJ, Batterham P, Perry T: Evolution, Expression, and Function of Nonneuronal Ligand-Gated Chloride Channels in Drosophila melanogaster. G3 (Bethesda) 2016, 6:2003-2012. Until two years ago several insect cysLGIC subunits had not been studied and therefore their function was unknown. This, therefore, is a welcome report shedding light on the function of the diverse subunits in the Insect Group 1 of cysLGIC subunits, which appear to be performing atypical non-neuronal roles.

[41] Feingold D, Starc T, O'Donnell MJ, Nilson L, Dent JA: The orphan pentameric ligand-gated ion channel $\mathrm{pHCl}-2$ is gated by $\mathrm{pH}$ and regulates fluid secretion in Drosophila Malpighian tubules. $J$ Exp Biol 2016, 219:2629-2638. - This successfully expressed an Insect Group 1 cysLGIC subunit and found that it does not respond to common neurotransmitters but is instead activated by a change in $\mathrm{pH}$, enhancing our knowledge about these divergent subunits.

[42] Pankova K, Borst A: RNA-Seq Transcriptome Analysis of Direction-Selective T4/T5 Neurons in Drosophila. PLoS One 2016, 11:e0163986.

[43] Frenkel L, Muraro NI, Beltran Gonzalez AN, Marcora MS, Bernabo G, Hermann-Luibl C, Romero $\mathrm{JI}$, Helfrich-Forster C, Castano EM, Marino-Busjle C, et al.: Organization of Circadian Behavior Relies on Glycinergic Transmission. Cell Rep 2017, 19:72-85. • It is well known that cysLGIC glycine 
receptors exist in vertebrates but their presence in insects is unclear. This paper identifies potential cysLGIC subunits functioning as glycine receptors in insects, thus highlighting another class of receptors in this gene superfamily.

[44] Morales-Perez CL, Noviello CM, Hibbs RE: X-ray structure of the human alpha4beta2 nicotinic receptor. Nature 2016, 538:411-415.

[45] Akdemir A, Rucktooa P, Jongejan A, Elk R, Bertrand S, Sixma TK, Bertrand D, Smit AB, Leurs R, de Graaf $C$, et al.: Acetylcholine binding protein (AChBP) as template for hierarchical in silico screening procedures to identify structurally novel ligands for the nicotinic receptors. Bioorg Med Chem 2011, 19:6107-6119.

[46] Hibbs RE, Gouaux E: Principles of activation and permeation in an anion-selective Cys-loop receptor. Nature 2011, 474:54-60.

[47] Wang NX, Watson GB, Loso MR, Sparks TC: Molecular modeling of sulfoxaflor and neonicotinoid binding in insect nicotinic acetylcholine receptors: impact of the Myzus beta1 R81T mutation. Pest Manag Sci 2016, 72:1467-1474.

[48] Mamta B, Rajam MV: RNAi technology: a new platform for crop pest control. Physiol Mol Biol Plants 2017, 23:487-501.

[49] Jones AK, Raymond-Delpech V, Thany SH, Gauthier M, Sattelle DB: The nicotinic acetylcholine receptor gene family of the honey bee, Apis mellifera. Genome Res 2006, 16:1422-1430.

[50] Jones AK, Sattelle DB: The cys-loop ligand-gated ion channel superfamily of the honeybee, Apis mellifera. Invert. Neurosci 2006, 6:123-132.

[51] Littleton JT, Ganetzky B: Ion channels and synaptic organization: analysis of the Drosophila genome. Neuron 2000, 26:35-43.

[52] Scott JG, Warren WC, Beukeboom LW, Bopp D, Clark AG, Giers SD, Hediger M, Jones AK, Kasai S, Leichter CA, et al.: Genome of the house fly, Musca domestica L., a global vector of diseases with adaptations to a septic environment. Genome Biol 2014, 15:466.

[53] Jones AK, Bera AN, Lees K, Sattelle DB: The cys-loop ligand-gated ion channel gene superfamily of the parasitoid wasp, Nasonia vitripennis. Heredity (Edinb) 2010, 104:247-259. 
Table 1. Insect species that have their complete cysLGIC superfamily described

\begin{tabular}{|l|l|l|l|l|}
\hline Species & Order & Significance & $\begin{array}{l}\text { cysLGIC subunit } \\
\text { gene number }\end{array}$ & Reference/s \\
\hline Aedes aegypti & Diptera & Disease vector & 25 & $\begin{array}{l}\text { (BJ Matthews } \\
\text { et al., } \\
\text { unpublished) }\end{array}$ \\
\hline Apis mellifera & Hymenoptera & $\begin{array}{l}\text { Pollination, honey } \\
\text { production }\end{array}$ & 21 & {$[49,50]$} \\
\hline $\begin{array}{l}\text { Acyrthosiphon } \\
\text { pisum }\end{array}$ & Homoptera & Crop pest & 22 & $\begin{array}{l}{[4], \text { (del Villar }} \\
\text { and Jones, } \\
\text { unpublished) }\end{array}$ \\
\hline Bombus impatiens & Hymenoptera & Pollination & 21 & {$[3]$} \\
\hline Bombus terrestris & Hymenoptera & Pollination & 21 & {$[3]$} \\
\hline $\begin{array}{l}\text { Drosophila } \\
\text { melanogaster }\end{array}$ & Diptera & $\begin{array}{l}\text { Genetic model } \\
\text { organism }\end{array}$ & 23 & {$[50,51]$} \\
\hline Musca domestica & Diptera & Disease vector & 23 & {$[52]$} \\
\hline $\begin{array}{l}\text { Nasonia vitripennis } \\
\text { Hymenoptera }\end{array}$ & $\begin{array}{l}\text { Biological control } \\
\text { of insect pests }\end{array}$ & 26 & {$[53]$} \\
\hline $\begin{array}{l}\text { Tribolium } \\
\text { castaneum }\end{array}$ & Coleoptera & $\begin{array}{l}\text { Pest of stored } \\
\text { food }\end{array}$ & 24 & {$[39]$} \\
\hline
\end{tabular}

\section{FIGURE LEGENDS}

Figure 1. Structure of a cys-loop ligand-gated ion channel (cysLGIC). Schematic representation of a heteromeric receptor consisting of two different subunits (dark and light grey). The peptide layout of two subunits are shown highlighting the Cys-loop (two white circles connected by a white double line) and four transmembrane domains. The six binding loops $(A-F)$ that contribute to ligand binding are shown and two neurotransmitter $(\mathrm{N})$ molecules are bound. The five subunits that make up the receptor are arranged around a central ion-permeable channel. The ions passing through the channel depend on the type of cysLGIC.

Figure 2. Tree showing the cys-loop ligand-gated ion channel (cysLGIC) gene families of $A$. pisum (pea aphid), Ae. aegypti (tiger mosquito) and B. terrestris (bumble bee). Based on their high amino acid sequence similarity, the cysLGIC subunits cluster together into groups according to their receptor type. 